\title{
Research on Agricultural Products Mobile Internet Marketing Strategies
}

\author{
Xue LI \\ Jilin Agricultural University, Changchun, Jilin, China \\ 50207681@qq.com
}

Li Xue: Jilin Agricultural University, No. 2888, Xincheng Street, Changchun, Jilin, 130000, 1981—,female, Han Nationality, master, lecturer

Key words: brand agricultural products; mobile Internet; marketing strategies

\begin{abstract}
On the basis of Chinese agricultural products brand strategies, it aims at characteristics of mobile Internet, constructs marketing strategy researches of brand agricultural products mobile Internet, promotes development road of brand agricultural products and improves competitiveness of agricultural products in international market. It utilizes interdisciplinary theoretical knowledge to do strategic researches on new economic mode development platform of mobile Internet and compares successful experiences of brand agricultural products' development of developed countries. Then, it changes to another way and proposes strategic modes suitable for Chinese brand agricultural products mobile Internet marketing on the mobile Internet economic mode with rapid development.
\end{abstract}

\section{Introduction}

Categories of Chinese brand agricultural products include regional brand agricultural products and corporate brand agricultural products with Internet as major medium. According to characteristics of Internet economic mobility, it formulates strategic strategies. According to the trend of mobile Internet development, it takes big data as basis and classifies target audiences to mobile-terminal, pad-terminal, vehicle-screen-terminal and wearable-terminal. It utilizes three entrances of mobile-terminal, e-commerce and games and realizes the cross-screen service ability of brand agricultural products in the air-sharing age.

1. Current status of Chinese brand agricultural products. According to the assessment reports of regional brand and corporate brand, it analyzes key elements that play decisive roles in brand agricultural products strategy. Based on brand agricultural products regional brand investigation data, it studies the current status of brand agricultural products regional brand development, analyzes and concludes characteristics and problems in development views, development trend, regional distribution, development speed, category concentration, product chain and management regulation and so on.

2. Current characteristics of mobile Internet. Firstly, according to trend of mobile Internet development, it takes big data as basis and classifies target audiences to mobile-terminal, pad-terminal, vehicle-screen-terminal and wearable-terminal. Secondly, it utilizes three entrances of mobile-terminal, e-commerce and games and realizes the cross-screen service ability of brand agricultural products in the air-sharing age. It organizes important elements that influence brand agricultural products marketing strategies and the macro perspectives are: humane elements, geographical elements, social elements, economic elements, political elements, technological and environmental elements; micro perspectives are supplier elements, purchaser elements, middleman elements, competitor elements, public elements, inner-enterprise elements. It combines elements that influence brand agricultural products marketing strategies, characteristics of mobile Internet target audiences and marketing strategies in traditional industries and constructs brand agricultural products mobile Internet marketing strategies from perspectives of marketing, brand science, management, communication, consumers' behaviors, agricultural economy, cultural economy and so on.

3. Aiming at brand agricultural products mobile Internet marketing strategies, it proposes mobile 
exploration platform of "mobile marketing scenes", "mobile module free combination" and "functional seamless upgrading" and combine functional modes according to demands.

(1) “Mobile marketing scenes” (1) Door-to-door service O2O. Consumers can enjoy door-to-door service by online reservation, which is suitable for users who have gardens in cities for services such as plowing, applying fertilizer and growing seedlings and so on. (2) Enterprise APP/ We-chat exploration demands. It is marketing windows for brand agricultural products enterprises to construct mobile-terminals and guide enterprises to conduct mobile marketing to win more opportunities. (3) Door-to-door service O2O, consumers place an order online and businessman deliver goods to your home. It is suitable for agriculture-connected supermarkets, fruits, fresh food and other agricultural products. (4) City tourism specialty O2O, residents, tourism companies and special operating service platforms; Consumers can understand local specialty, tourism consultation, food consultation and so on from mobile app and enjoy specialty commodity pushing service provided by brand agricultural products enterprises; it is suitable for tourism company's innovative transition. (5) E-commerce helps brand agricultural products enterprises to broaden online marketing channels, establish independent and exclusive mobile commerce to obtain members and manage members better. (6) Group purchase $\mathrm{O} 2 \mathrm{O}$ helps consumers to locate merchants of brand agricultural products. (7) Community $\mathrm{O} 2 \mathrm{O}$ is a new community service platform for city residents and surrounding relaxation agriculture from which residents can understand consultation information of relaxation agriculture, agricultural relaxed environment and enjoy agricultural life and experience services provided by brand agricultural products enterprises. (8) Game O2O is an online agricultural products game platform. It integrates agricultural products planting, breeding and other production experiences, games and entertainment, in which brand agricultural products advertisements are implanted.

(2) Functional module: (1) Convenient payment: supporting code-scanning account transfer, code-scanning payment, online mall payment, takeaway payment. It is convenient for consumers to purchase and promote stores' service quality. (2) Advertisement interaction: supporting vouchers, discount coupons and coin certificates, which brings benefits to users and more new users to stores. (3) Bargaining propagation: helping to bargain: guide users to propagate products and win more new users in a short time. (4) Meeting interaction: promoting atmosphere of the meeting and audiences' participation, improving corporate image and brand popularity. (5) Shaking sales promotion: opening Bluetooth and Wechat and you can shake to pay attention, shake the advertisements, shake introduction, shake vote and shake to sign up. It renders participation feeling to users and form interactions with stores. (6) Shaking to sign up: when you see advertisements you are interested in, you can shake to sign up; targeted delivery is more reliable.

It is a brand-new innovative research project to conduct comprehensive and systemic research on agricultural brand marketing strategies, construct mobile Internet marketing strategies analysis framework with Chinese characteristics and upgrade it to theoretical mode and practical layer. It has established the relationship between brand agricultural products, mobile Internet and marketing strategies scientifically. Various important elements overlap and intersect, which realizes Internet promotion model of brand agricultural products economic development, thereby being a new exploration of challenges. It involves multidisciplinary theoretical knowledge and perspectives of marketing, brand science, management, communication, consumers' behaviors, agricultural economy, cultural economy and so on. Constructing brand agricultural products mobile Internet marketing strategies is quite innovative.

Most of the previous researches are conducted under agricultural brand strategies. This paper takes mobile Internet as the starting point, conducts comprehensive and systemic theoretical and empirical researches on Chinese brand agricultural products, which represents the new perspective. The research content is innovative. Researches on mobile Internet commercial mode and innovation discusses from strategic positioning, value orientation, demand innovation, product and service, creating a valuable open platform, ecological system, socialized marketing and profit model, which has strong reality pertinence and operability and represents new content. This project has strong 
reality and practicalness, so it pays attention to the combination of theoretical researches and empirical researches as well as the combination of literature researches and field researches. Based on the special demands of the project, it pays more attention to empirical researches and investigation.

\section{Reference}

[1]Yao Chunling. Agricultural and Industrial Cluster and Agricultural Products Regional Brand Competitiveness Promotion Strategies. Agricultural Modernization Research, 2013 (3)

[2]Zhang Chuantong. Study of Influence Factors of Agricultural Products Regional Brand Purchase Intention. Soft Science, 2014（10）

[3]Lin Derong. Growth Path and Influence Factor Research of Agricultural Regional Public Brand__-Taking "Yantai Apple” as an Example. Qingdao Agricultural University Journal, 2012 (2)

[4]Yao Chunling. Agricultural and Industrial Cluster and Agricultural Products Regional Brand Competitiveness Promotion Strategies. Agricultural Modernization Research, 2013（3）

[5]Liu Xuefei. Basic Experiences and Enlightenment of Foreign Agricultural Products Brand Construction, World Agriculture, 2014（6） 